Gut, 1964, 5, 315

\title{
Reticulum cell sarcoma of the small bowel and steatorrhoea
}

\author{
DOUGLAS EAKINS, TERENCE FULTON, AND DAVID R. HADDEN \\ From the Department of Pathology, The Queen's University of Belfast, and \\ the Royal Victoria Hospital, Belfast
}

EDITORIAL SYNOPSIS This series presents further evidence for an association between reticulosis of the intestine and steatorrhoea. Although some patients have a definite past history of gluten enteropathy, it seems likely that in certain patients the reticulosis itself is the primary cause of the steatorrhoea.

For 25 years after the account by Fairley and Mackie (1937) of a sprue-like syndrome occurring in patients with intestinal reticuloses, the latter were accepted as a rare cause of secondary steatorrhoea. Ten years ago Sleisenger, Almy, and Barr (1953) reviewed the literature and described four patients of their own all of whom they considered to be suffering from secondary steatorrhoea. In 1962 Gough, Read, and Naish considered these and later case reports and added three of their own. They came to the conclusion that many were cases of idiopathic steatorrhoea which had developed reticulosis as a late complication. Current interest in the association between reticulosis and steatorrhoea is reflected in the reports of 11 cases which have appeared during the past two years bringing the total number to just under forty.

Between June 1955 and March 1963 we have seen six patients suffering from reticulum cell sarcoma, five of whom presented with steatorrhoea in late middle life, while the sixth patient in all probability had coeliac disease from childhood. These cases emphasize the need to consider the possibility of reticulosis in this age group, illustrate the difficulties in confirming the clinical suspicion of its presence, and, even with the information provided by biopsy or necropsy, demonstrate the difficulty in deciding whether the primary lesion was idiopathic steatorrhoea or reticulosis.

\section{CASE REPORTS}

CASE 1 Early in April 1955, R.M., a previously healthy 49-year-old housewife, lost her appetite and felt sick and easily tired. Four weeks later she began to vomit small quantities of greenish liquid several times each day. In mid-May she developed severe diarrhoea, passing 10 to 12 liquid, often greenish, inoffensive motions in the day. She had no tenesmus or abdominal pain, nor did she observe any blood or mucus in the motions. She became feverish with shivering and sweating. The skin over the entire body became dry and scaly.

On admission to the Royal Victoria Hospital in late June she was anaemic, wasted, and ill. With the exception of the face the skin was generally dry and leathery and there was extensive desquamation. A mosaic of fine fissures extended down towards the dermis. The tongue was smooth and red and there was angular stomatitis. The nails were brittle and there was a tendency to koilonychia. None of the superficial lymph nodes was enlarged. There was persistent sinus tachycardia and the blood pressure was $110 / 75 \mathrm{~mm}$. $\mathrm{Hg}$. The abdomen was soft, doughy, and tympanitic with predominantly central distension. The liver edge could be felt 2 to 3 fingerbreadths below the costal margin in full inspiration and the tip of the spleen came down 1 fingerbreadth. A firm, mobile mass, approximately $4 \mathrm{~cm}$. in diameter, was felt deeply within the abdomen. Sometimes it was situated to the right of the umbilicus, whereas on other occasions it was located above or to the left of it. There was an irregular pyrexia up to $104^{\circ} \mathrm{F}$.

Bence-Jones protein was detected in the urine. E.S.R.s of 25 and $7 \mathrm{~mm}$. in one hour (Westergren) were recorded. Haemoglobin was 8.7 g. $/ 100 \mathrm{ml}$., M.C.V. $78 \mathrm{c} \mu$, M.C.H.C. $30 \%$, and white cells $3,800 /$ c.mm. (32\% neutrophils, $1 \%$ eosinophils, $65 \%$ lymphocytes, and $2 \%$ monocytes). Examination of the bone marrow did not show infiltration by abnormal cells but changes in both the myeloid and erythroid series were compatible with antimegaloblastic factor deficiency. The serum total protein level was $6.0 \mathrm{~g} . / 100 \mathrm{ml}$. and serum albumin $3.6 \mathrm{~g} . / 100 \mathrm{ml}$. The prothrombin concentration was $13 \%$. Blood culture was negative and no pathogenic organisms were grown from the stools. On a normal low-residue diet the daily faecal fat content varied between 11.8 and $36.4 \mathrm{~g}$.

Supportive treatment with blood transfusion, fluid and electrolyte replacement, vitamin supplements, and other symptomatic measures caused initial slight improvement in her general condition with diminution of the diarrhoea 
but the pyrexia and skin desquamation continued and the surface epithelium of the tongue and lips separated. Vaginal bleeding developed and purpuric lesions appeared on the arms. Her condition rapidly deteriorated and she died on 12 July, four months after symptoms commenced. At necropsy a mass of large, white, fleshy lymph nodes was present in the jejunal mesentery and some of the para-aortic, mediastinal, and cervical lymph nodes were also involved. The normal architecture was replaced by large reticulum cells and there were also occasional giant cells. There was no macroscopic evidence of ulceration or tumour invasion of the bowel wall at any level. Autolysis precluded histological examination for tumour invasion or villous atrophy. Fatty changes were present in the liver but there was no tumour involvement. The spleen was enlarged (200 g.) and there was a general increase in reticulum cells. The bone marrow was active and free of tumour cells.

CASE 2 In April 1956, W.A., a previously healthy 58-year-old joiner, developed crampy abdominal pain and passed two or three liquid motions daily. His appetite deteriorated and he lost weight. The only abnormal findings three weeks later were pallor and swelling of the ankles. The E.S.R. was $15 \mathrm{~mm}$., serum total protein $5.5 \mathrm{~g} . / 100 \mathrm{ml}$. (serum albumin $3.3 \mathrm{~g} . / 100 \mathrm{ml}$.), haemoglobin 12.5 g./100 ml., M.C.V. $108 \mathrm{c} \mu$, M.C.H.C. $34 \%$, and white cells $3,900 / \mathrm{c} . \mathrm{mm}$. with a normal differential count. Except for irritability of the caecum barium enema was normal.

Symptomatic treatment seemed to be entirely effective and he remained in good health until March 1957 when his symptoms returned. When in March 1958 he eventually agreed to attend hospital for further investigation he looked pale and wasted and weighed only $130 \mathrm{lb}$. Swelling of the ankles was present and on rectal examination the faeces were noted to be pale.

The E.S.R. was $49 \mathrm{~mm}$., haemoglobin $11.0 \mathrm{~g} . / 100 \mathrm{ml}$., M.C.V. $117 \mathrm{c} \mu$, M.C.H.C. $32 \%$, and white cells 5,000 /c.mm. Bone marrow examination showed megaloblastic erythropoiesis. The serum total protein was $6.7 \mathrm{~g} . / 100 \mathrm{ml}$. and albumin $3.8 \mathrm{~g}$. $/ 100 \mathrm{ml}$. Free hydrochloric acid was present in the gastric juice and radioactive vitamin $B_{12}$ absorption tests gave a result in keeping with malabsorption. The fat content of the faeces was $49.2 \mathrm{~g}$. $/ 100 \mathrm{~g}$. dried weight but barium meal examination did not show any abnormality in the upper gastro-intestinal tract and the small bowel pattern was normal. Barium enema again showed no definite abnormality and stool examinations for occult blood were negative.

Treatment with folic acid, vitamin $\mathrm{B}_{\mathbf{1 2}}$, iron, vitamin $\mathrm{C}$, and a fat-restricted diet was followed by a remission lasting for over three years. Appetite improved, weight increased, and energy returned. The diarrhoea ceased and the stools became normal. In May, July, and October 1958 E.S.R.s of 35,11 , and $5 \mathrm{~mm}$. were recorded. In March 1960 the figure was $9 \mathrm{~mm}$. and the haemoglobin was $13.9 \mathrm{~g} . / 100 \mathrm{ml}$.

Treatment was continued and he remained well until July 1961 when he lost his appetite and became sick and feverish. His weight fell to $112 \frac{1}{2} \mathrm{lb}$. He developed crampy

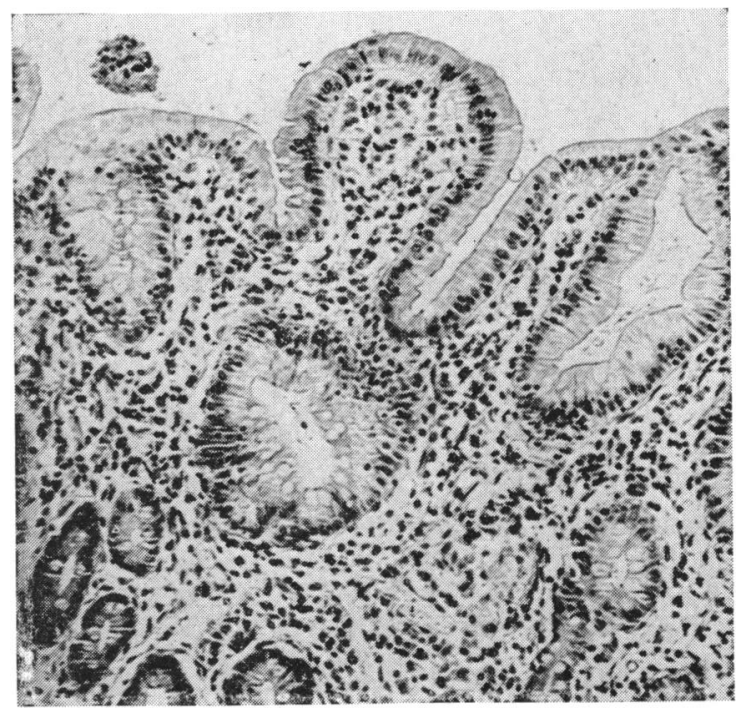

FIG. 1. Case 2. Jejunal mucosa showing partial villous atrophy. $\times 240$.

transabdominal pain followed by diarrhoea and passed three or four pale, loose, offensive motions daily. Discomfort in the left hypochondrium became increasingly troublesome, especially on deep breathing. Slight fullness appeared in this region and persistent gurgling peristaltic sounds could be heard.

The E.S.R. had increased to $38 \mathrm{~mm}$. and the haemoglobin had fallen to $11.7 \mathrm{~g} . / 100 \mathrm{ml}$., R.B.C.s to $4 \cdot 13$ million/c.mm. and M.C.H.C. to $30 \%$. The serum total protein was $5.8 \mathrm{~g} . / 100 \mathrm{ml}$., with $2.6 \mathrm{~g}$. of albumin and normal globulin fractions. Bone marrow examination did not disclose any excess of reticulum cells. Barium meal examinations showed segmentation, multiple fluid levels, and 24-hour retention of the contrast medium in the dilated proximal loops of the jejunum but no filling defect could be identified. Stool examination for occult blood gave three weakly positive and two negative reactions.

On 4 August signs of intestinal perforation appeared and at laparotomy Mr. Terence Kennedy found multiple perforating ulcers in the upper part of the jejunum. The mesenteric lymph nodes were enlarged and fleshy but the liver, spleen, and the remainder of the bowel appeared normal. With difficulty the pathological segment was resected and end-to-end anastomosis effected. After a stormy post-operative period he made a gradual recovery and was discharged from hospital at the end of September. The diarrhoea ceased, he gained $8 \mathrm{lb}$. and when seen in October there were no symptoms or abnormal physical findings. He died at home in December 1961 of bronchopneumonia and necropsy was not performed.

The portion of jejunum removed at operation in August measured $110 \mathrm{~cm}$. There were multiple perforations and the changes of acute peritonitis were present. Although there was no macroscopic evidence of tumour in the bowel wall histological examination showed it to be 
heavily infiltrated with large, darkly staining cells characteristic of reticulum cell sarcoma. Partial villous atrophy was present (Fig. 1). The few lymph nodes examined were not involved by tumour.

CASE 3 On 22 December 1958 T. McC., a 50-year-old insurance salesman, had sudden diarrhoea with nausea and abdominal pain. He improved with symptomatic measures but when seen by Dr. D. A. D. Montgomery in February 1959 he was complaining of tiredness and crampy abdominal pain and was passing four or five watery motions daily. Clinical examination was normal.

The E.S.R. was $18 \mathrm{~mm}$., haemoglobin $12.6 \mathrm{~g} . / 100 \mathrm{ml}$., M.C.V. 96 c $\mu$, M.C.H.C. $30 \%$, and white cells $8,500 /$ c. $\mathrm{mm}$. with a normal differential count. The serum total protein was $4.3 \mathrm{~g} . / 100 \mathrm{ml}$. and serum albumin $2.0 \mathrm{~g}$./ $100 \mathrm{ml}$. The stools were loose, pale and bulky but the fat content was reported to be only $5 \cdot 1 \mathrm{~g}$. $/ 24$ hours on a $70 \mathrm{~g}$. per day fat intake. Barium meal and follow-through examination showed dilatation of the jejunum and flocculation and clumping of the contrast in the ileum. Barium enema disclosed no abnormality and stool examinations for occult blood were negative.

Within four weeks his weight had fallen by 1 stone to $126 \mathrm{lb}$. and ankle oedema had appeared. Following admission to hospital in March 1959 he developed acute appendicitis and simple appendicectomy was performed. Histological examination showed only the changes of acute inflammation. One week later without warning he went into sudden peripheral circulatory failure which responded to treatment with noradrenaline and hydrocortisone.

At the end of April 1959 there was considerable oedema of both legs and the serum total protein level was $3 \cdot 1$ g. $/ 100 \mathrm{ml}$. with albumin $1.3 \mathrm{~g} . / 100 \mathrm{ml}$. and generally reduced globulin fractions. Treatment with a high-protein, low-fat, sodium-restricted diet was instituted and during the next few weeks his condition improved considerably with cessation of diarrhoea and disappearance of oedema. The serum total protein rose to 6.0 g./100 ml. with albumin $2 \cdot 8 \mathrm{~g}$. $/ 100 \mathrm{ml}$. On this dietary régime his weight increased to $136 \mathrm{lb}$. during the next two months.

He continued to pass pale, bulky stools, however, and had two further attacks of gaseous abdominal distension, vomiting, and diarrhoea, the second of which led to his re-admission in August 1959. His weight had fallen to $128 \frac{1}{2} \mathrm{lb}$. but with the exception of central abdominal distension no significant abnormality was found. Haemoglobin was 11.7 g. $/ 100 \mathrm{ml}$, M.C.V. 97 c $\mu$, M.C.H.C. $31 \%$, and white cells $9,700 /$ c.mm. Serum electrolytes were well maintained but the serum total protein level had fallen to $3.9 \mathrm{~g} . / 100 \mathrm{ml}$. with albumin $1.8 \mathrm{~g} . / 100 \mathrm{ml}$. Faecal fat excretion amounted to $14 \cdot 1$ g./24 hours. Barium studies showed only general dilatation of the small bowel and no localized obstructive lesion was detected. Treatment with a gluten-free diet was instituted and his condition gradually improved, weight increasing to $136 \mathrm{lb}$. and the motions returning to normal. Serum total protein and albumin levels increased to $5.8 \mathrm{~g}$. and $2 \cdot 8 \mathrm{~g} . / 100 \mathrm{ml}$. respectively.

This remission lasted for only a few weeks and in
January 1960 recurrence of symptoms necessitated a further six weeks' stay in hospital. He was apyrexial and there was no appreciable change in the clinical or haematological findings. The E.S.R. was $5 \mathrm{~mm}$., serum total protein $4.2 \mathrm{~g}$. $/ 100 \mathrm{ml}$., albumin $2.2 \mathrm{~g} . / 100 \mathrm{ml}$., and serum carotene $11 \cdot 3 \mu \mathrm{g} . / 100 \mathrm{ml}$. Eight stool examinations for occult blood were negative.

Diarrhoea, abdominal distension, and attacks of vomiting continued during the next three months in spite of the gluten-free diet and he became wasted and developed clubbing of the fingers. Further investigations failed to clarify the situation and at laparotomy on 2 June $1960 \mathrm{Mr}$. R. H. Livingston found only distension of both small and large bowel and a large calcified gland in the mesentery of the terminal ileum. Histological examination of this and a neighbouring gland showed nonspecific reactive changes. Post-operatively his symptoms regressed and his condition improved. As a precautionary measure he was given a short course of anti-tuberculous therapy.

In August 1960 the various symptoms gradually returned and his condition deteriorated despite treatment with prednisone. The number of motions increased to seven per day, the stools being fluid and offensive, and three or four times daily he vomited small quantities of sour yellow liquid. On final admission to hospital in October 1960 he was emaciated and weighed only $98 \mathrm{lb}$. There was glossitis, clubbing of the fingers, peripheral oedema and generalized brownish pigmentation of the skin. The abdomen was swollen and tympanitic and peristaltic waves could readily be seen passing along the coils of small bowel.

Faecal fat content varied between 13 and $80 \mathrm{~g}$. in 24 hours. Normal quantities of trypsin were present in the faeces and repeated examination showed no evidence of Giardia lamblia or Entamoeba histolytica. Gastric acidity was high and 12-hour fasting gastric aspirations produced as much as $1,230 \mathrm{ml}$. containing $75 \mathrm{mEq}$./litre of free $\mathrm{HCl}$. Duodenal aspirations showed $p \mathrm{H}$ levels as low as 3.6. The presence of a protein-losing enteropathy was confirmed by excretion in the faeces of $3.33 \%$ of the administered dose of ${ }^{131}$ I-polyvinyl pyrrolidone in five days.

On 19 January 1961 a second laparotomy was performed by Mr. R. H. Livingston and Professor R. B. Welbourn. There was some free fluid in the peritoneal cavity and the retroperitoneal tissues were oedematous. No abnormality was found in the bowel wall or pancreas. Splenectomy, partial pancreatectomy, vagotomy, and pyloroplasty were undertaken and multiple biopsies obtained. Post-operative recovery was satisfactory but at the beginning of April 1961, in spite of full supportive therapy, the symptoms increased and for the first time during his long hospital stay he became feverish. Signs of bronchopneumonia developed and he died 28 months after the onset of his illness.

The biopsy specimens of mesenteric lymph nodes, small bowel, liver, pancreas, and spleen obtained at the second laparotomy showed no evidence of tumour. At necropsy, however, histological examination of the enlarged white mesenteric lymph nodes revealed complete replacement of the normal architecture by a proliferation 
of reticulum cells and a marked degree of necrosis. The cells were pleomorphic with large hyperchromatic nuclei. There was no macroscopic evidence of tumour in the small bowel but histological examination of random sections showed reticulum cell infiltration in all layers with areas of superficial mucosal ulceration. Partial villous atrophy was present. Similar tumour tissue was noted in sections of the liver and lung.

CASE 4 O.S., a 63-year-old retired school teacher, was well until February 1958 when she began having bouts of diarrhoea alternating with periods of constipation. In April splenomegaly and macrocytic anaemia were noted and injections of vitamin $B_{12}$ were given. During the summer she felt better but in October 1958 the bowel symptoms returned and continued without remission until her death a year later. In February and March 1959 she had paraesthesiae in the feet and in June she developed glossitis. Her appetite deteriorated and when in August 1959 she was admitted to the Royal Victoria Hospital under the care of Dr. D. A. D. Montgomery her weight had fallen by $35 \mathrm{lb}$. to $135 \mathrm{lb}$.

On examination she was thin and pigmented and was running an intermittent pyrexia up to $101^{\circ} \mathrm{F}$. There was gaseous distension of the abdomen and the lower pole of the spleen could be felt 3 fingerbreadths below the left costal margin. Signs of mild peripheral neuritis were present in the legs.

The E.S.R. was $9 \mathrm{~mm}$., haemoglobin $11.2 \mathrm{~g} . / 100 \mathrm{ml}$,, M.C.V. $106 \mathrm{c} \mu$, M.C.H.C. $34 \%$, and white cells $2,200 /$ c. $\mathrm{mm}$. with a normal differential count. Reticulocytes numbered $5 \%$. Bone marrow was normal except for a few macronormoblasts. Serum total protein was $4.4 \mathrm{~g}$./ $100 \mathrm{ml}$., with albumin $2.2 \mathrm{~g} . / 100 \mathrm{ml}$. and generally reduced globulin fractions. Serum carotene was $26 \mu \mathrm{g}$. $/ 100$ ml., calcium 7.9 g. $/ 100 \mathrm{ml}$., and alkaline phosphatase $13 \mathrm{~K}$.A. units. On a $70 \mathrm{~g}$. per day fat intake the fat content of the faeces was $82 \mathrm{~g} . / 100 \mathrm{~g}$. dried weight and barium studies showed dilatation of the small bowel with barring and clumping of the contrast as seen in steatorrhoea. Frequent stool examinations for pathogenic organisms and occult blood were negative. Free hydrochloric acid was secreted by the stomach. After $50 \mathrm{~g}$. of glucose by mouth the maximum rise of blood sugar was $5 \mathrm{mg} . / 100 \mathrm{ml}$. at two hours. Radiographs of the lumbo-sacral spine showed mild osteoporosis.

Treatment with a gluten-free diet, folic acid, vitamin supplements, vitamin $\mathbf{B}_{12}$, blood transfusion, and neomycin failed to halt the downhill course. By the end of September her weight had fallen to $101 \mathrm{lb}$., the liver was enlarged 3 fingerbreadths below the costal margin, and she had developed an indolent ulcer on the gum. During the second half of October the evening temperature spiked to $102^{\circ}-103^{\circ} \mathrm{F}$. and she had heavy night sweats. E.S.R.s of 14 and $6 \mathrm{~mm}$. were recorded during this period and the white cell count remained at 2,200/c.mm. but the haemoglobin fell to $9.4 \mathrm{~g} . / 100 \mathrm{ml}$. and M.C.H.C. to $28 \%$.

At exploratory laparotomy by Mr. J. W. S. Irwin on 26 October 1 litre of straw-coloured fluid was found in the peritoneal cavity and there was firm generalized enlargement of the liver and spleen. Arising in a loop of small bowel and infiltrating the fundus of the bladder

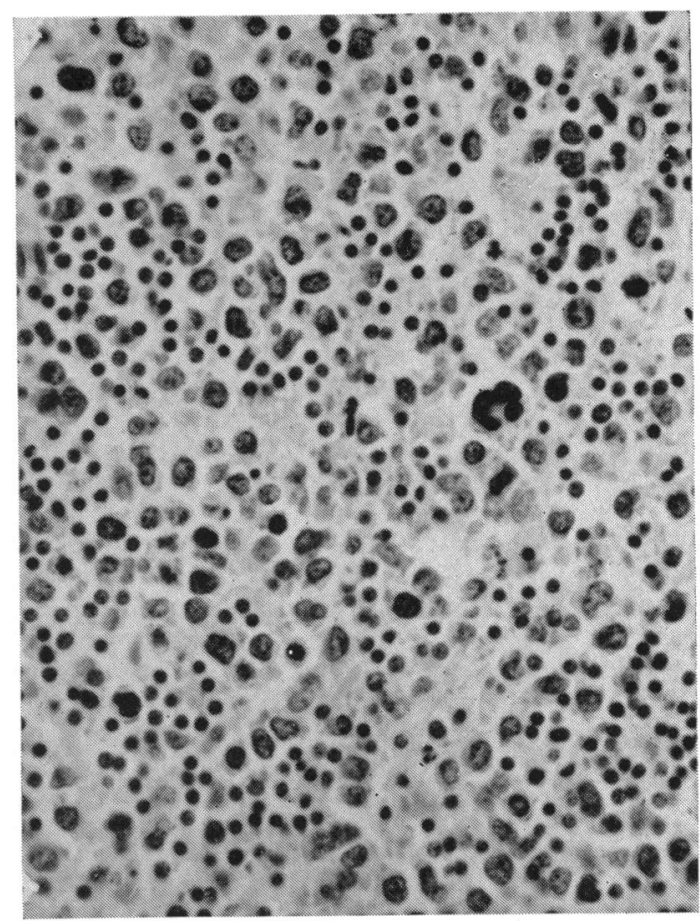

FIG. 2. Case 4. Infiltration of bowel wall with reticulum cell sarcoma. $\times 330$.

was a tumour mass the size of a cricket ball. Several neighbouring loops of small bowel were adherent to it. On its mucosal aspect the tumour formed an ulcer $7 \cdot 5 \mathrm{~cm}$. in diameter. The adjacent mesenteric lymph nodes were enlarged and fleshy. With difficulty a segment of small bowel measuring $67 \mathrm{~cm}$. was excised along with the mesenteric glands arid end-to-end anastomosis was performed. Nine days after the operation, however, the patient died and permission for necropsy was not obtained.

Examination of the surgical specimen showed that the tumour mass in the wall of the bowel had caused some narrowing of the lumen. Histological examination showed diffuse infiltration of the wall of the small bowel (Fig. 2) and complete replacement of the mesenteric lymph nodes by reticulum cell sarcoma. Partial villous atrophy was present and was more marked in areas of tumour infiltration.

CASE 5 M.McV., a 61-year-old housewife, had during the previous 10 years been treated intermittently with topical and systemic cortisone derivatives for sarcoidosis affecting the eyes, parotid glands, larynx, and skin. Except for chronic bronchitis, complicated in April 1958 by basal pneumonia, her general condition remained satisfactory until early April 1961. At that time she lost her appetite, felt tired and weak and developed epigastric pain, vomiting, and diarrhoea. Symptomatic treatment was quickly effective but she remained easily tired and in September her symptoms all returned. Crampy lower abdominal pain was accompanied by diarrhoea and she 
passed five to seven pale, frothy, offensive motions per day. She became thirsty, rapidly lost weight, and developed right saphenous phlebitis.

On admission to the Royal Victoria Hospital in midNovember 1961 she was wasted and had a smooth tongue. The skin was dry and scaly, a mosaic of fine cracks extended down through the epidermis and there was extensive desquamation. During the first 10 days in hospital she had intermittent pyrexia up to $101^{\circ} \mathrm{F}$. There were no findings in the abdomen and in spite of repeated examination it was not until four weeks after admission that a firm, tender mass was felt below and to the right of the umbilicus.

The haemoglobin was 12.5 g. $/ 100 \mathrm{ml} .$, M.C.V. $102 \mathrm{c} \mu$, M.C.H.C. $31 \%$, and white cells, $9,400 /$ c.mm. with a normal differential count. Examination of the bone marrow showed normoblastic erythropoiesis though occasional megaloblasts and giant metamyelocytes indicative of antimegaloblastic factor deficiency were seen. E.S.R.s of 20, 7, and $10 \mathrm{~mm}$. were recorded. Serum carotene was $36 \mu \mathrm{g} . / 100 \mathrm{ml}$., blood pyruvate $1.18 \mathrm{mg} . / 100$ ml., serum calcium $8.6 \mathrm{mg} . / 100 \mathrm{ml}$., and serum total protein $4.1 \mathrm{~g} .100 \mathrm{ml}$. with reduction of all fractions. Formiminoglutamic acid was detected in the urine. Fat excretion in the stools amounted to $11.6 \mathrm{~g}$./24 hours. Tests for occult blood were negative. Barium meal and enema showed no mucosal abnormality of intrinsic bowel lesion. Radiographs of the skeleton were normal.

Treatment with a gluten-free diet, nandrolone, folic acid, vitamin $\mathbf{B}_{12}$, and other vitamin supplements was given. The sickness and abdominal pain ceased and the diarrhoea improved considerably but phlebitis spread to the right popliteal and femoral veins and anticoagulant therapy was initiated. Following the discovery of the abdominal mass, however, laparotomy was performed on 5 January by Mr. E. W. McMechan. The wall of the entire small bowel was found to be extensively infiltrated by tumour nodules and the nodes at the root of the mesentery formed a large, fixed mass. Post-operatively irreversible hypotension developed and death occurred within 24 hours.

At necropsy the femoral and external iliac veins were occluded by antemortem thrombi and emboli were found in many pulmonary vessels including the right main pulmonary artery. Histological examination of the liver, spleen, bone marrow, and superficial lymph nodes disclosed no evidence of tumour. The mesenteric lymph nodes were infiltrated by tumour tissue and formed a mass in the ileo-caecal region measuring $9 \mathrm{~cm}$. in diameter. There were tiny tumour nodules on the serosal surface of the small bowel and mucosal infiltration and ulceration by reticulum cell sarcoma had occurred at many levels. Partial villous atrophy was present. Apart from fibrosis of the parotid glands there were no residual lesions of Boeck's sacroid.

CASE 6 J.W., a 59-year-old clerk, had rickets at the age of 13 and, in comparison with his siblings, growth and development were slow. From the age of 20 the stools were loose, bulky, pale, and offensive. He first attended the Royal Victoria Hospital in 1949 because of anorexia, weight loss, and symptoms of anaemia. The R.B.C. count was 3.5 million/c.mm. and the colour index 1.25. Injections of liver extract caused a satisfactory haematological response. Early in 1952, however, the symptoms reappeared but he did not return to hospital until August 1953. At that time he had a pale, sallow complexion and clubbing of the fingers. He weighed only $112 \frac{1}{2} \mathrm{lb}$. There was evidence of old rickets with splaying out of the lower ribs but no findings were noted in the abdomen.

The E.S.R. was $8 \mathrm{~mm}$., haemoglobin $13.3 \mathrm{~g} . / 100 \mathrm{ml}$., and film normal. Barium meal examination showed appearances typical of idiopathic steatorrhoea. A fractional test meal showed achlorhydria.

Treatment with a protein-reinforced, fat-restricted diet, vitamin supplements, folic acid, and injections of vitamin $B_{12}$ was instituted but he failed to attend for review and allowed therapy to lapse. His appetite deteriorated and he developed flatulent dyspepsia. Weight fell to $98 \mathrm{lb}$. and symptoms of anaemia reappeared. He complained of a sore tongue and continued to pass offensive bulky stools. It was not until October 1957, however, that he agreed to attend hospital for further investigation.

The findings on examination were emaciation, anaemia, a smooth pale tongue, and firm enlargement of the liver. The E.S.R. was $58 \mathrm{~mm}$., haemoglobin $7.9 \mathrm{~g} . / 100 \mathrm{ml}$., M.C.V. $130 \mathrm{c} \mu$, and M.C.H.C. 32\%. Bone marrow examination showed megaloblastic erythropoiesis with giant metamyelocytes. The serum total protein was $6.3 \mathrm{~g} . / 100 \mathrm{ml}$., albumin $3.5 \mathrm{~g} . / 100 \mathrm{ml}$, , and calcium $8.9 \mathrm{mg} . / 100 \mathrm{ml}$. After $50 \mathrm{~g}$. of glucose by mouth the maximum rise of blood sugar was $54 \mathrm{mg} . / 100 \mathrm{ml}$. at two hours.

The response to treatment with folic acid and vitamin supplements was satisfactory and during the next three months weight increased to $110 \frac{1}{2} \mathrm{lb}$. The haemoglobin rose more slowly, reaching $12.5 \mathrm{~g}$. in June 1958. E.R.S.s of $17,1,9$, and $5 \mathrm{~mm}$. were recorded during this eightmonth period.

He failed to reattend and was not seen again until March 1961 when he was admitted following an episode of myocardial infarction. Haematological examination showed an iron-deficiency anaemia. The previous régime of treatment was reinstituted and he was given a short course of anticoagulant therapy but on review in August 1961 it was evident that he had again allowed treatment to lapse.

Following a successful operation for cataract in March 1962 nothing more was heard of him until January 1963 when he was readmitted because of sudden severe pain in the upper abdomen radiating into the loins. The pain, which was accompanied by pronounced constipation, was worse immediately after meals. A large, firm, mobile, tender mass could be felt in the epigastrium and left hypochondrium and pressure over it reproduced his pain. Part of the mass appeared to be fixed to the posterior abdominal wall but the major portion moved with respiration. There was no abdominal distension, hyperperistalsis, or splenomegaly but the liver was slightly enlarged. The tip of the nose was cyanotic and he had marked palmar erythema, clubbing, and atrophy of the skin over the backs of the fingers. His weight was now $94 \mathrm{lb}$. and height only 61 inches and he had the typical triangular-shaped face of long-standing steatorrhoea. 
The E.S.R. was $20 \mathrm{~mm}$., haemoglobin $11.3 \mathrm{~g} . / 100 \mathrm{ml}$., M.C.V. $91 \mathrm{c} \mu$, M.C.H.C. $33 \%$, and white cells 7,300/c. $\mathrm{mm}$. Serum bilirubin was $1.1 \mathrm{mg} . / 100 \mathrm{ml}$, alkaline phosphatase 12 K.A. units, calcium $7.7 \mathrm{mg} . / 100 \mathrm{ml}$., phosphorus $3.4 \mathrm{mg} . / 100 \mathrm{ml}$., carotene $27 \mu \mathrm{g} . / 100 \mathrm{ml}$., total protein $6.9 \mathrm{~g} . / 100 \mathrm{ml}$. and albumin $3.9 \mathrm{~g} . / 100 \mathrm{ml}$. On a $70 \mathrm{~g}$. per day fat intake the faecal fat content over a three-day period was reported to be $1.29 \mathrm{~g}$. but this result did not accord with the appearance of the stools which were bulky and pale. Barium studies showed widening of the duodenal loop with stretching of the third part of the duodenum but there was no evidence of an intrinsic lesion of the small bowel and the appearances were entirely consistent with malabsorption. Radiographs of the spine and pelvis showed loss of bone density. After $50 \mathrm{~g}$. of glucose by mouth the maximum rise of blood sugar was $18 \mathrm{mg} . / 100 \mathrm{ml}$. at two-and-a-half hours. No formiminoglutamic acid was detected in the urine. Only $5 \%$ of the oral test dose or radioactive vitamin $B_{12}$ was excreted in the urine in $\mathbf{4 8}$ hours and the simultaneous

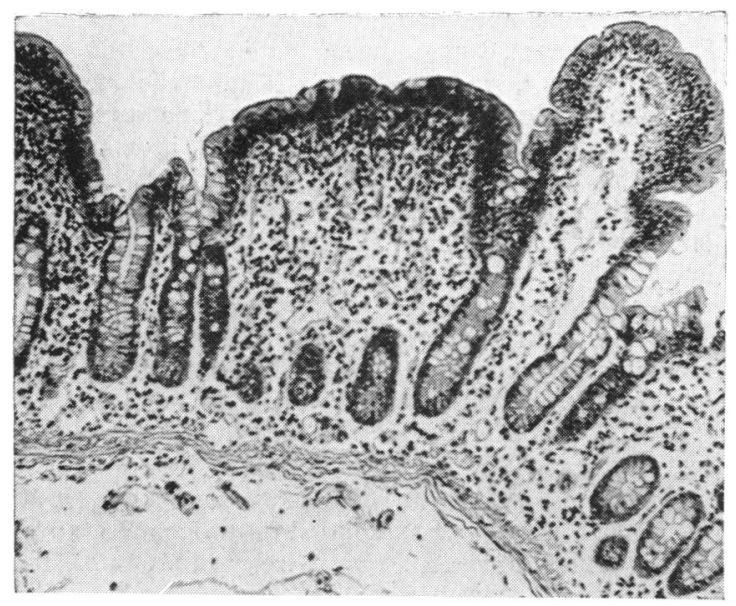

FIG. 3. Case 6. Jejunal biopsy specimen showing partial villous atrophy. $\times 110$.

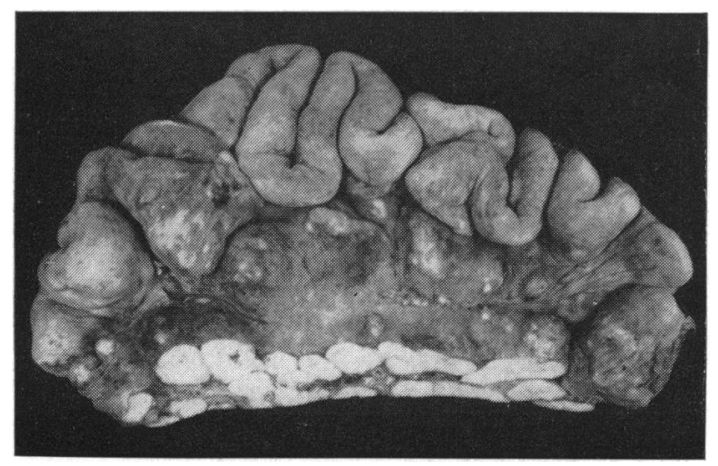

FIG. 4. Case 6. Heavy infiltration of jejunal wall and mesenteric lymph nodes with tumour. administration of intrinsic factor failed significantly to improve this result.

The clinical diagnosis of reticulosis of the small bowel complicating coeliac disease was confirmed at laparotomy by Professor H. W. Rodgers. There were tumour deposits in the omentum and a hard mass of enlarged mesenteric glands. Post-operatively his condition gradually deteriorated and he died on 14 March 1963.

At necropsy there was extensive infiltration of both the jejunum and ileum. Lengths of the bowel wall of up to $10 \mathrm{~cm}$. were replaced by tumour tissue and there was ulceration of the overlying mucosa. Partial villous atrophy was evident throughout the small bowel (Fig. 3). Tumourinfiltrated mesenteric lymph nodes formed a large, rigid mass occupying the posterior portion of the abdomen (Fig. 4). The mediastinal and cervical lymph nodes were also infiltrated by tumour but were enlarged to a much lesser extent. Histological examination showed tumour infiltration of the liver, spleen, and bone marrow. The appearances in all the affected tissues were typical of a reticulum cell sarcoma. The left coronary artery contained a recanalized thrombus and there was an old myocardial infarct in the postero-lateral wall of the left ventricle.

\section{ANALYSIS OF CASES}

AGE AT ONSET OF SYMPTOMS The commencement of symptoms between the ages of 49 and 63 years in five of our six patients closely corresponds to the age distribution noted by Sleisenger et al. (1953) in their analysis of 17 cases of the sprue syndrome associated with lymphoma of the small bowel. It contrasts with Badenoch's (1960) cases of idiopathic steatorrhoea only $18 \%$ of which were in this age group. Five of our patients had symptoms for less than two years when first seen, the average length of history being nine months, and none of them had the skeletal changes associated with long-standing malabsorption. If these are cases of idiopathic steatorrhoea complicated by reticulum cell sarcoma of the small bowel, as Gough et al. (1962) suggest, it is noteworthy how remarkably silent the primary condition remained over the years, symptoms only commencing on average 26 months before death. In our sixth patient, however, symptoms began in childhood and the skeletal deformities of old rickets were present.

FEATURES COMPATIBLE WITH IDIOPATHIC STEATORRHOEA Initial symptoms, including anorexia, nausea, vomiting, diarrhoea, abdominal discomfort, tiredness, and weight loss, did not differ from those encountered in patients suffering from idiopathic steatorrhoea. Five patients had generalized brownish pigmentation of the skin and, in addition, cases 1 and 5 showed the changes of ichthyosis and erythrodermia (Wells, 1962). Finger clubbing occurred in cases 3 and 6. 
Radiological studies of the small bowel were made in five of the six patients but in none could a lesion of the wall be demonstrated. In one the appearances were essentially normal but all the others showed the typical changes seen in idiopathic steatorrhoea. The faecal fat content was within the range found in this condition. In three patients repeated tests for occult blood were negative and in only one were weakly positive reactions obtained. Four patients had macrocytic anaemia with bone marrow changes indicative of antimegaloblastic factor deficiency and one patient had an irondeficiency anaemia.

Partial villous atrophy of the small bowel (Shiner, 1959) was present in some degree in five of the cases and was more pronounced in areas of tumour infiltration than in adjacent areas free of tumour. In the remaining case autolysis precluded assessment of villous morphology.

FEATURES SUGGESTIVE OF RETICULOSIS Noteworthy features in this small series were Bence-Jones proteinuria in one case, splenomegaly in two cases, hepatomegaly in two cases, and a palpable abdominal mass in four cases, though in cases 4,5 , and 6 the latter only became apparent shortly before laparotomy. Cooke, Peeney, and Hawkins (1953) found mild splenomegaly in 11 of their 100 cases of idiopathic steatorrhoea, but we considered the large size of the spleen in case 4 to be highly suggestive of reticulosis and the hepatomegaly and abdominal mass confirmed this clinical impression. Apart from these findings there were no clinical indications of reticulosis. There was, for example, no evidence of tumour involvement of the superficial lymph nodes or bone marrow. However, necropsy revealed the presence of tumour outside the abdominal cavity in cases 1,3 , and 6.

The diagnostic significance of severe abdominal pain as an indication of small bowel reticulosis has been emphasized by Gough et al. (1962) and was a prominent feature in two of our patients but occurred very late in the clinical course. In case 2 it corresponded to the stage of penetration and obstruction of the bowel and in case 6 it appeared to be due to stretching of the mesentery by the large tumour deposits.

Pyrexia varying from $101^{\circ}$ to $104^{\circ}$, present in four of our six cases, was a late manifestation in two of them and in one corresponded to the stage of penetration and perforation of the bowel wall. Gough et al. (1962) stated that reticulosis should be suspected in patients with steatorrhoea who suffer a clinical relapse with pyrexia and raised sedimentation rate. In cases 2 and 6 E.S.R.s of 49 and $58 \mathrm{~mm}$. were recorded three and a quarter and five and a quarter years before the presence of reticulosis was confirmed. In the other four cases, however, the E.S.R. was not elevated above $25 \mathrm{~mm}$. during the course of their illness and in three cases figures of 10,7 , and $6 \mathrm{~mm}$. were recorded within three weeks of operation or necropsy at a time when the reticulosis was well established.

In three patients the serum total protein level was reduced to $5.0 \mathrm{~g} . / 100 \mathrm{ml}$. and in five of the six patients the albumin fraction was $3.5 \mathrm{~g} . / 100 \mathrm{ml}$. or less. Adlersberg, Wang, and Bossak (1957) found the serum total protein level to be less than $5 \mathrm{~g}$. $/ 100 \mathrm{ml}$. in $19.4 \%$ of 60 patients with idiopathic steatorrhoea and the serum albumin level was below $3.5 \mathrm{~g} .1100 \mathrm{ml}$. in $51.8 \%$. In cases 2 and 3 serum total protein and albumin levels appeared to be influenced by treatment with diuretics and a high-protein, fat-restricted, gluten-free diet but a general trend to increasing hypoalbuminaemia and consequent hypoproteinaemia was evident during the course of the disease. In fact, with the exception of cases 2 and 6, appropriate dietary and therapeutic measures failed to produce the expected remission and progressive deterioration occurred.

\section{DISCUSSION}

In the majority of the cases of lymphoma of the small bowel associated with steatorrhoea which have been recorded during the past 10 years the tumour was a reticulum cell sarcoma (Friedlander and Gorvy, 1955; French, Hawkins, and Smith, 1957; Culver, Benson, Strauss, and Jones, 1959; Girdwood, Delamore, and Williams, 1961; Best and Cook, 1961; Gough et al., 1962; Spracklen for Tonkin, 1963; Amman, 1963). A similar neoplasm was present in all of our cases and localization of the main mass of the tumour within the abdomen was a noteworthy feature. The small bowel was usually severely affected and in two cases multiple foci of tumour were present, suggesting a multicentric origin. The mesenteric lymph nodes were extensively infiltrated, and dissemination beyond the abdomen was also by lymphatic channels with involvement of the mediastinal and cervical lymph nodes. The extent of involvement decreased the further from the abdomen the tumour was found. This distribution of tumour, which occurred consistently in our cases, coincides well with the main lymphatic absorptive pathway and thus theoretically with the entry and spread of a carcinogen from the small bowel. Blood-borne metastasis appears to occur late in these cases.

Mesenteric lymph node replacement by tumour is no longer accepted as a cause of serious malabsorption nor can the extent of mucosal infiltration often 
account for it. In some cases it may be due to severe mucosal ulceration or to alteration of the bowel flora, but in others an underlying defect of absorption is present. Diarrhoea, the usual presenting symptom, together with a variable degree of steatorrhoea, could be due to the reticulum cell sarcoma itself, a primary malabsorptive disorder or the unmasking effect of the former on a pre-existing and hitherto occult defect of absorption.

The absence of mucosal villi (subtotal villous atrophy) is considered by some (Fone, Cooke, Meynell, Brewer, Harris and Cox, 1960; Cooke, Cox, Jones, and Meynell, 1963; Scudamore, 1963) to be characteristic of adult coeliac disease while varying degrees of villous atrophy, possibly resulting from a secondary deficiency state, occur in certain other conditions associated with malabsorption. The hypothesis of Gough et al. (1962) that reticulum cell sarcoma is a specific complication of idiopathic steatorrhoea would be greatly strengthened if it could be shown that subtotal villous atrophy was the mucosal change usually found in these cases. In our small series, however, the mucosal appearances were those of partial rather than subtotal villous atrophy and the changes were invariably more pronounced in those areas of the mucosa which were infiltrated by tumour.

It might have been expected that any causal relationship between coeliac sprue and reticulosis of the small bowel would be most apparent in patients with florid and longstanding steatorrhoea. However, we have noted in the literature only three cases of reticulosis occurring in patients with the clinical features of coeliac disease and only two in patients known to have had idiopathic steatorrhoea for more than 10 years. These figures are small compared with the frequency of coeliac disease and idiopathic steatorrhoea and it could be contended that the association is one of chance alone. The absence of steatorrhoea in the 1,269 cases of reticulosis reported by Rosenberg, Diamond, Jaslowitz, and Craver (1961) would also seem to support such a conclusion. However, an indication that the association may be more frequent than these figures suggest is shown by the fact that of the five cases noted above four have been reported during the past two years. Moreover in the majority of patients the symptoms of steatorrhoea were of short duration and the total length of the illness was in keeping with the natural history of the reticulosis itself. Those few patients with a long history of malabsorption had relatively mild symptoms and reached the sixth and seventh decades often without rigid dietitic or supplementary treatment. This somewhat unexpected clinical course may have an important bearing on the pathogenesis of the reticulum cell sarcoma and may also be an aid to the diagnosis of its presence.

Mucosal enzymatic defects, whether genetically determined or the result of cellular damage, may on the one hand result in the characteristic deficiencies of absorption seen in coeliac sprue and on the other, by alteration of the mucosal barrier, permit the absorption of abnormal substances with carcinogenic properties. There may be little correlation between these two effects in individual cases and a reticulosis may arise in the absence of florid symptoms and signs of malabsorption. Moreover the reticulosis itself may have a detrimental influence on the already impaired absorptive mechanism and, by unmasking a hitherto occult defect, may account for the very short history of steatorrhoea in some of these cases. The prolonged deficiency of important nutrients such as folic acid may also predispose to the development of reticulosis which might then be expected to occur, especially in patients with subclinical malabsorption in whom the need for folic acid therapy was not recognized. In our series of cases it seems unlikely that radiation played any role in the pathogenesis of the reticulosis.

It is disturbing that the reticulosis often causes no specific symptoms and routine investigations may fail to confirm its presence. It should, however, be suspected in patients manifesting steatorrhoea for the first time in the sixth and seventh decades and in those suffering from longstanding coeliac sprue who unaccountably relapse while receiving treatment which had previously been effective. Important diagnostic features are an abdominal mass, enlargement of the liver or spleen, severe colicky central abdominal pain, unexplained pyrexia, a raised E.S.R. and otherwise unexplained small bowel perforation. Nevertheless laparotomy may be necessary to make the diagnosis and to permit definitive treatment of those patients with a localized tumour but even laparotomy may occasionally fail to establish the presence of reticulosis.

We wish to express our thanks to Professor J. H. Biggart, Dr. W. T. E. McCaughey and Dr. J. Willis for their helpful criticism and advice; to Dr. T. H. Crozier, Dr. D. A. D. Montgomery and Dr. J. A. Weaver for allowing us to include cases 3,4 , and 6 who were admitted to hospital under their care; and to Mr. D. Mehaffey for photographing the sepcimens.

\section{REFERENCES}

Adlersberg, D., Wang, C. I., and Bossak, E. T. (1957). J. Mt Sinai Hosp., 24, 206-220.

Amman, R. (1963). Malabsorption Syndromes. Symposium, 2nd World Congress of Gastroenterology, Munich, p. 16. Karger, Basel.

Badenoch, J. (1960). Steatorrhoea in the adult. Brit. med. J., 2, 879-887.

Best, C. N., and Cook, P. B. (1961). Case of mesenteric reticulosarcoma associated with gluten-sensitive steatorrhoea. Ibid., 2, 496-498. 
Cooke, W. T., Cox, E. V., Jones, C. T., and Meynell, M. J. (1963). Temperate Sprue. Symposium, 2nd World Congress of Gastroenterology, Munich, pp. 8-10. Karger, Basel.

—, Peeney, A. L. P., and Hawkins, C. F. (1953). Symptoms signs, and diagnostic features of idiopathic steatorrhoea. Quart. $J$. Med., 22, 59-77.

Culver, P. J., Benson, J. A. Jr., Strauss, E., and Jones, C. M. (1959). Some observations on the malabsorption syndrome, based on the use of absorption tests and biopsy of the small intestine. Gastroenterology, 36, 459-466.

Fairley, N. H., and Mackie, F. P. (1937). The clinical and biochemical syndrome in lymphadenoma and allied diseases involving the mesenteric lymph glands. Brit. med. J., 1, 375-380.

Fone, D. J., Cooke, W. T., Meynell, N. J., Brewer, D. B., Harris, E. L., and Cox, E. V. (1960). Jejunal biopsy in adult coeliac disease and allied disorders. Lancet, 1, 933-938.

French, J. M., Hawkins, C. F., and Smith, N. (1957). The effect of a wheat-gluten-free diet in adult idiopathic steatorrhoea. Quart. J. Med., 26, 481-499.

Friedlander, P. H., and Gorvy, V. (1955). Steatorrhoea. Brit. med. J., 2, 809-812.
Girdwood, R. H., Delamore, I. W., and Williams, A. W. (1961). Jejunal biopsy in malabsorptive disorders of the adult. Ibid., 1, 319-323.

Gough, K. R., Read, A. E., and Naish, J. M. (1962). Intestinal reticulosis as a complication of idiopathic steatorrhoea. Gut, $\mathbf{3}$, 232-239.

Rosenberg, S. A., Diamond, H. D., Jaslowitz, B., and Craver, L. F (1961). Lymphosarcoma: a review of 1,269 cases. Medicine (Baltimore), 40, 31-84.

Scudamore, H. H. (1963). An evaluation of secondary malabsorption syndromes of intestinal origin. Symposium, 2nd World Congress of Gastroenterology, Munich, pp. 11-16. Karger, Basel.

Shiner, M. (1959). Small intestinal biopsy: diagnostic and research value. Proc. roy. Soc. Med., 52, 10-14.

Sleisenger, M. H., Almy, P. T., and Barr, D. P. (1953). The sprue syndrome secondary to lymphoma of the small bowel. Amer. J. Med., 15, 666-674.

Spracklen, F., for Tonkin, R. D. (1963). Reticulosis of the small bowel as a late complication of idiopathic steatorrhoea. Proc. roy. Soc. Med., 56, 167-168.

Wells, G. C. (1962). Skin disorders in relation to malabsorption. Brit. med. J., 2, 937-943. 